\title{
Rare Occurrence of Four Rooted Maxillary Third Molar: A Case Report
}

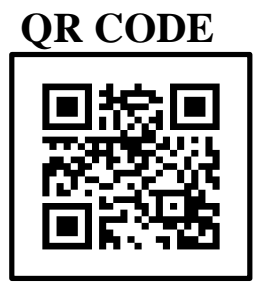

\section{SHASHANK YADAV}

This case report presents a rare variant of maxillary third molar variant, which had four roots. A 48-year-old male patient complained about severe pain in his left maxillary tooth region of the jaw. A clinical intraoral inspection and radiography were carried out on the tooth, and a diagnosis of chronic apical periodontitis was made. An uneventful extraction was performed for the same.

KEYWORDS: Maxillary Third Molar, Four Roots, Rare Occurrence

\section{INTRODUCTION}

For a complete and successful root canal therapy, careful identification and localization of root canals is of prime importance. The maxillary molar usually is a three rooted tooth. It is a rare occurrence that the maxillary molars have four roots. Last maxillary molars are teeth of special clinical interest as they present with wide horizon of anatomical disparity in their roots. Different morphological configurations of the maxillary second molar have been documented before in a few studies. ${ }^{1-4}$ The incidence of molars with four roots are reported to be less than $1 \% .5$ The treatment of a third molar with aberrant root configuration can pose a diagnostic and clinical challenge to the dentist. The clinical relevance and the purpose of this work is to report the extraction of a rarely occurring four rooted maxillary third molar.

\section{CASE REPORT}

A 48 year old male patient presented to us with the chief complaint of pain in the upper back left tooth since the last 1 and a half month. The pain was primary in incidence, sudden in onset, intermittent in frequency, aggravated on chewing food, relieved by removal of stimulus. The pain did not radiate to any other regions of the face or neck. The medical history was not significant. The general physical examination and extra-oral examination were non-contributory. Intra-oral examination of the involved tooth revealed deep proximal caries with respect to tooth number 28 . On palpation, the tooth had grade I mobility. On vertical percussion, the tooth was tender. Mouth opening was significantly reduced. The soft tissue examination revealed no abnormality.
The investigations performed were complete blood count (CBC), Intra-oral periapical radiograph of 28 (Figure 1). The radiograph revealed a diffuse radiolucency w.r.t the mesial aspect of the occlusal surface of 28 involving the enamel, dentin and pulp. The radicular portion revealed widening of periodontal ligament space with intact lamina dura suggestive of apical periodontitis w.r.t to 28 . The patient was explained about the condition and a decision for extraction of the offending tooth was finalized. After providing local anesthesia by giving a nerve block using 2\% lidocaine with 1:80,000 epinephrine, extraction was performed. On extraction, it was observed that the molar has four roots (Figure 2).

\section{DISCUSSION}

Apparently, all teeth in the dental arch have a certain tendency of occurrence of extra roots. ${ }^{6}$ The presence of a maxillary molar with four roots is significantly less frequent. Although the incidence of four rooted maxillary molars is rare, but they still have a occurrence probability. ${ }^{7}$ The proper diagnosis and treatment plan is critically essential for a appreciative outcome. Variations in the root morphology may range from one rooted to four rooted molars. The IOPAR taken for diagnosing the current case was not clear due to limited mouth opening, thus the fourth root remained unrevealed until extraction. The horizontally angled radiographs can also be of great help in distinguishing the multiple root morphology of molars. ${ }^{7}$ A classification of four-rooted maxillary molars has been described in literature: type I are those with long, tortuous and divergent palatal 
roots; type II have short blunt and parallel roots; and type III are the one with three convergent roots and a distinctly divergent fourth distobuccal root. ${ }^{8}$ The tooth treated in this case appears to most likely fall into their type III classification. The presence of maxillary molar with double palatal roots is a rare phenomenon and is most frequently limited to maxillary second molar. Many reports and clinical studies concerning second maxillary molar with 4 roots have been published. Libfeld and Rostein ${ }^{7}$ conducted a survey on 1200 maxillary second molars and found out $0.4 \%$ of the sample to have this condition. Peikoff et al. ${ }^{9}$ reported the frequency of this kind of variation to be around $1.4 \%$. Sidow SJ et al. ${ }^{10}$ investigated and characterized the anatomy of 150 maxillary and mandibular third molars and found out that $7 \%$ of maxillary molars had four roots. Cases of four rooted maxillary $2^{\text {nd }}$ molars ${ }^{6}$ or those with an extra palatal $\operatorname{root}^{11,12}$ have also been reported in literature. We conclude that the dental practitioners should have a pre-knowledge of anatomic variability of roots, especially an awareness and understanding regarding the possible presence of an additional root with unusual morphology. This is an essential point in determining the successful outcome of dental treatment for such variable teeth.

\section{CONCLUSION}

Atypical root configurations should always be expected, as they present a challenge for successful dental treatment. A dental practitioner should always be observant, as variability in root anatomy might be confronted at any time during treatment. This paper may escalate the complicatedness of maxillary third molar variation and is intended to supplement dental clinicians' awareness of the variable root morphology. There is need to carry out cross-sectional studies to investigate the number of roots in the maxillary third molar with special emphasis on the occurrence of four roots.

\section{REFERENCES}

1. Vertucci FJ. Root canal anatomy of the human permanent teeth. Oral Surg 1984;58:589-99.

2. Sert S, Bayirli G. Evaluation of the root canal configurations of the mandibular and maxillary permanent teeth by gender in the Turkish population. J Endod 2004;30:391-8.

3. Caliskan MK, Pehlivan Y, Sepetcioglu F, Turkun M, Tuncer SS. Root canal morphology of human permanent teeth in a Turkish population. J Endod 1995;21:200-4.

4. Alavi AM, Opasanon A, Ng YL, Gulabivala K. Root and canal morphology of Thai maxillary molars. Inter Endod J 2002;35: 478-85.

5. Cleghorn BM., et al. "Morphology of teeth and their root canal systems". In: Ingle J, Bakland L, editors. Ingle's Endodontics. Hamilton: BC Decker Inc; (2008): 151-220.

6. Slowey RR. Radiographic aids in the detection of extra root canals. Oral Surg 1974;37:762-72.

7. Libfeld H, Rotstein I. Incidence of four rooted maxillary second molars; literature review and a radiographic survey of 1200 teeth. J Endodon 1989; 15:129-31.

8. Christie WH, Piekoff MD, Fogel HM. Maxillary molars with palatal roots; a retrospective clinical study. J Endodon 1991;17:80-4.

9. Peikoff MD, Christie WH and Fogel HM. The maxillary second molar: Variations in the number of roots and canals. Int Endod J 1996;29(6):365-9.

10. Sidow SJ, West LA, Liewehr FR, Loushine RJ. Root canal morphology of human maxillary and mandibular third molars. J Endod 2000;26(11):675-8. 11. Jong TE. Doubling of the palatal root in the second and third upper molars. Ned Jijdsch Tandhee 1965;72-7.

12. Stone LH, Stroner WF. Maxillary molars demonstrating more than one palatal root canal Oral Surg 1981;51:649-52. 
Source of support: Nil, Conflict of interest: None declared
Cite this article as:

Yadav S. Rare Occurrence of Four Rooted Maxillary Third Molar: A Case Report. Int Healthcare Res J 2018;1(10):320-322.

\section{AUTHOR AFFILIATIONS:}

BDS, Private Practitioner

\section{Corresponding Author:}

Dr. Shashank Yadav

Shri Ji Dental Clinic

Plot No. 54

Shivpuram Satbari Road,

Koyala Nagar, Kanpur

For article enquiry/author contact details, e-mail at:

manuscriptenquiry.ihrj@gmail.com

\section{LEGENDS}

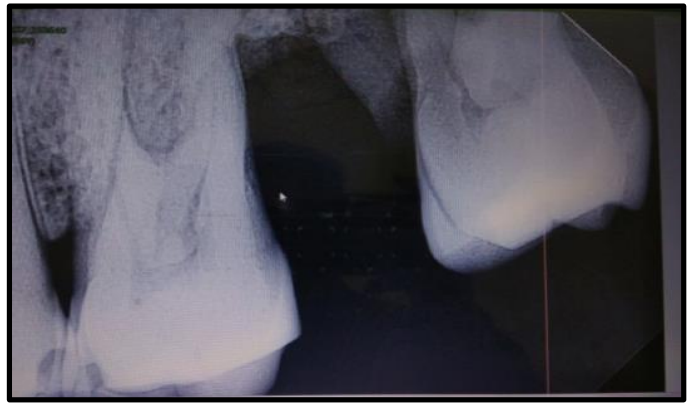

Figure 1. Intra-Oral Periapical Radiograph of Tooth Number 28

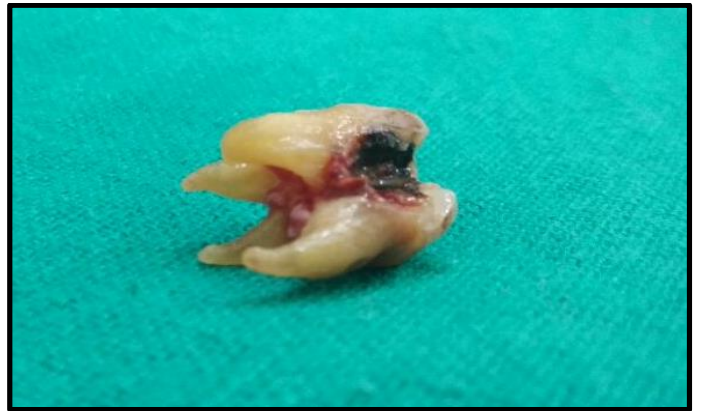

Figure 2. Extraction of the Affected Tooth Revealed Four Roots (Rare Occurrence) 